\title{
A Review of Hepatitis B Management in Pre- and Post-Liver Transplant Recipients
}

\author{
Sandeep Mukherjee*
}

Section of Gastroenterology and Hepatology, University of Nebraska Medical Center, Omaha, Nebraska, USA

\begin{abstract}
Liver transplantation was approved for treatment of decompensated cirrhosis in the United States in 1983. Hepatitis B and hepatitis C viruses are the leading causes of liver transplantation for viral hepatitis and hepatitis B is also an important cause of liver transplantation for called acute liver failure) due to either acute hepatitis B or an acute exacerbation of chronic hepatitis B. However, until the introduction of hepatitis B immunoglobulin and nucleoside/nucleotide analogues nearly twenty years ago, liver transplantation for hepatitis B was characterized by universal recurrence with a dismal prognosis. The widespread use of oral anti-virals in the US has led to a decreased incidence of decompensated liver disease and patients waitlisted for liver transplantation. Among patients listed for hepatocellular carcinoma, the decrease in waitlist registration was also least dramatic among patients with HBV, possibly related to the use of oral antivirals. At present, liver transplantation for hepatitis B, regardless of whether for decompensated cirrhosis, hepatocellular carcinoma satisfying Milan criteria or acute liver failure has excellent outcomes with results comparable if not better to other liver transplant recipients. This article will review the management of patients with decompensated cirrhosis from HBV prior to liver transplantation, the use of hepatitis B positive donors and the prevention and management of hepatitis B after liver transplantation.
\end{abstract}

Keywords: Hepatitis B, nucleos(t)ide, decompensated cirrhosis, liver transplantation, prophylaxis, hepatitis B immune globulins.

\section{INTRODUCTION}

Approximately two billion of the world's population are infected with chronic hepatitis B (HBV) of whom 350 million have ongoing infection [1]. Although HBV is not endemic in the United States, some features on the epidemiology of this disease merit further discussion [2]. For example, the trend for listing patients for HBV-related liver disease has been declining in the United States since it peaked in 2000 with nearly $30 \%$ reduction in subsequent years according to registry data from the United Network for Organ Sharing (UNOS). The largest decrease in patients on the waiting list for liver transplantation (LT) occurred in patients with decompensated cirrhosis whereas the number of patients with hepatocellular carcinoma (HCC) increased. One possible explanation for these trends is the widespread use of antivirals for HBV, particularly lamivudine which was introduced in the late 1990's. This was supported by a recent retrospective studying the impact of anti-viral therapies on waitlist registration for patients with viral hepatitis [3]. The investigators reported that of 113,927 waitlist patients, 4,793 (4.2\%) had HBV. Furthermore, the incidence of waitlist registration for decompensated cirrhosis and acute liver failure (ALF) decreased whereas that for HCC increased. Interestingly, the decrease in registration for decompensated cirrhosis was most pronounced and the increase in HCC least dramatic among registrants with HBV. These findings were indicative that population-wide application of oral antiviral

*Address correspondence to this author at the Section of Gastroenterology and Hepatology, 983285 Nebraska Medical Center, Omaha, NE 681983285, USA; Tel: 402-559-8859; Fax: 402-559-3434;

E-mail: smukherj@unmc.edu therapy for HBV contributed to the decreased incidence of decompensated liver disease.

Indications for liver transplantation for $\mathrm{HBV}$ include decompensated cirrhosis, HCC and ALF. ALF may sometimes be difficult to distinguish from severe exacerbations of chronic HBV which occur spontaneously during the immune reactive phase of chronic HBV or may be reactivated by immunosuppressive medications or chemotherapy [4-6]. A large number of cases of reactivation are subclinical and resolve spontaneously or result in chronic hepatitis which may go undetected until patients present with decompensated cirrhosis. The importance of reactivation rests not only on its potential life-threatening complications but the ease of its prevention with oral antiviral therapy [7].

\section{GUIDELINES FOR THE MANAGEMENT OF HEPATITIS B}

In 2008, the European Association for the Study of Liver Diseases (EASL) published clinical practice guidelines and revised recommendations for the management of chronic HBV [8]. The guidelines divided treatment into short-and long-term strategies. Finite treatment with interferon-based therapy is recommended for those with the highest chance of achieving a sustained response when therapy is completed. Finite treatment with nucleosides/nucleotides is also considered for $\mathrm{HBV}$ e antigen ( $\mathrm{HbeAg}$ ) positive patients who achieve seroconversion during therapy. Long-term therapy with nucleosides/nucleotides is only recommended for patients unable to achieve a sustained viral response when therapy is discontinued. The EASL guidelines also emphasize that when choosing an oral therapy, preference should be given to anti-virals which are potent and have a 
low incidence of developing drug-resistance in naïve patients, such as entecavir and tenofovir [9]. The EASL guidelines concluded with the following 12 unresolved issues that required further study:

1. Improvement in the knowledge of the natural history of immunotolerant patients with long-term follow-up of cohorts; experimental studies to provide more definite prognostic information and biomarkers to determine prognosis and indications for treatment.

2. Development and assessment of new therapeutic approaches, particularly immunomodulatory therapies to enhance loss of $\mathrm{HBeAg}$ and $\mathrm{HBsAg}$ and subsequent seroconversion.

3. Assessing the role of indirect markers (serum and biophysical) to assess the severity of liver disease and for the follow-up of treated and untreated patients.

4. Assessing the role of HBV genotype to determine prognosis and response to therapy and the risk of resistance.

5. Assessing the efficacy of different durations (24 weeks to 2 years) and lower doses of pegylated interferon alpha.

6. Assessing long-term efficacy and safety and resistance profiles to new analogues (entecavir, telbivudine and tenofovir).

7. Better definition of monitoring algorithms: timing of HBV DNA measurement with the new generation of nucleosides with a high genetic barrier to resistance; role of genotypic resistance assays in adapting therapy.

8. Assessing the role of combination therapy with 2 nucleosides to reduce resistance.

9. Assessing the efficacy of the combination of pegylated interferon alpha with potent nucleosides (entecavir or tenofovir) to increase $\mathrm{HBe}$ and $\mathrm{HBs}$ seroconversion rates.

10. Development of new drugs to manage multiresistant HBV resistant to both lineages of current NUC's.

11. Assessing long-term impact of therapy on the prevention of cirrhosis and its complications and HCC.

12. Developing effective and optimum treatment for HDV infection.

The National Institutes of Health (NIH) convened a conference in October 2008 to reach consensus on the management of chronic HBV [10]. A central aim of the task force was to evaluate available randomized controlled trials on anti-viral therapy for chronic HBV between 1990 and 2008. A key but somewhat controversial conclusion of the review was that available data did not provide sufficient information required for decision-making in the long-term treatment of chronic HBV. For example, the panel concluded that randomized controlled trials looked at short term results and surrogate markers such as normalization of liver function tests, suppression of HBV deoxyribonucleic acid (DNA) and improvement in liver histology but few studies assessed the impact of treatment on risk of hepatic decompensation, HCC or death. However, it is important to reiterate that the $\mathrm{NIH}$ is not suggesting that clinicians should abstain from treating HBV but rather that data from available randomized studies was not available to confirm the effects of HBV therapy on clinical outcomes.

In December 2008, an expert panel of hepatologists published a treatment algorithm for the management of chronic HBV [11]. The Keeffe panel recommended entecavir, tenofovir and pegylated interferon alfa- $2 \mathrm{a}$ as the preferred first line treatment for chronic HBV. The panel stated that all three therapies demonstrated superior efficacy and safety over comparators in pivotal clinical trials in HbeAg- positive and negative patients. The panel did not recommend lamivudine despite its excellent safety profile due its high rate of drug resistance and data clearly demonstrating superiority of entecavir to lamivudine. They recommended that tenofovir should substitute for adefovir as a first line agent but stated that the role of telbivudine was unclear.

\section{MANAGEMENT OF DECOMPENSATED CIRRHOSIS FROM CHRONIC HEPATITIS B}

Until the development of hepatitis B immunoglobulin (HBIG) and oral anti-virals, the presence of active HBV replication was considered a contraindication to LT as severe recurrent disease was universal. The introduction of antivirals in decompensated cirrhotics had several advantages including deferring LT in a proportion of patients whose clinical condition improved and reducing or clearing HBV DNA prior to LT and thus decreasing the development of recurrent disease after LT [12]. As interferon-based treatment is contraindicated in decompensated cirrhotics, only nucleoside/nucleotide analogues have been evaluated in these patients.

\section{Lamivudine}

Several studies have evaluated the impact of lamivudine, a nucleoside analogue which inhibits viral polymerase, on HBV replication in decompensated liver disease. Although lamivudine is well-tolerated even in patients with advanced liver disease and can achieve rapid viral suppression the incidence of drug resistance is approximately $20 \%$ per year [13]. In a multicenter study of 77 patients treated with lamivudine $100 \mathrm{mg}$ per day, Perrillo et al. reported that lamivudine was partly effective in preventing recurrent HBV infection when administered before and after LT [14]. Patients in this study were treated while on the waiting list and continued after LT - although all patients were HBV surface antigen (HbsAg) positive, 61\% were eAg-positive with detectable HBV DNA. 47 patients underwent LT and 30 did not. In the transplanted group, $59 \%$ of patients were HbsAg-positive at treatment week 156 and all 9 reinfected patients were HBV DNA positive before treatment. In the non transplant group, HbeAg was initially detectable in $74 \%$ of patients but decreased to $18 \%$ after 108 weeks of treatment. HBV DNA polymerase mutations were noted in $21 \%$ and $20 \%$ of transplanted and non-transplanted patients, respectively. Although this prospective study was limited by an absence of a control arm, the investigators concluded that lamivudine-treated patients appeared to have improved survival and transplanted patients had a decreased incidence of recurrent $\mathrm{HBV}$ compared to historical controls. 
A prospective, multicenter trial by Fontana et al. also evaluated the impact of lamivudine on 154 patients listed for LT [15]. $21 \%$ of patients died during the study with the majority of deaths $(78 \%)$ occurring in the first 6 months of therapy. In multivariate analysis, the severity of liver disease prior to initiation of lamivudine was a better predictor of early mortality than the virological response to lamivudine and the investigators recommended that regardless of the response to lamivudine, patients with decompensated cirrhosis should be transplanted promptly.

Although most of the studies evaluating lamivudine therapy with post-LT outcomes for HBV consistently recommend antiviral therapy should be started as soon as possible due to significant clinical improvement from antivirals, the high rate of drug-resistance with lamivudine remains problematic, particularly as the incidence of resistance increases the longer treatment is continued. This in turn has led to cases where LT has been performed in lamivudine -resistant cases with controversial outcomes and reports of recurrence occurring in a graft despite the use of lamivudine with HBIG post-LT [16, 17]. Lamivudine is well-tolerated with few side effects and has clearly played an important role in the management of decompensated cirrhotics prior to LT-however, the high incidence of viral resistance not observed with the new generation of nucleoside/nucleotide antivirals will likely make it obsolete in the near future.

\section{Adefovir}

Adefovir dipivoxil is a nucleotide analogue of adenosine monophosphate which inhibits both wild type and lamivudine-resistant HBV. Due to the high incidence of resistance reported with lamivudine, the introduction of adefovir was both timely and life-saving for many patients. A landmark study by Schiff et al. treated 128 decompensated patients with lamivudine-resistance with adefovir $10 \mathrm{mg}$ per day for a median of 18 weeks [18]. 81\% achieved undetectable HBV DNA which was associated with normalization of serum alanine aminotransferase (ALT) in $76 \%$ of patients who had elevated baseline ALT. This was associated with an improvement in clinical status and Childs Pugh Score (CPS) in $90 \%$ of patients and a 1 year survival of $84 \%$ which compared favorably with historical controls.

An important aspect of this study was the long-term follow-up results which were reported in wait-listed $(n=226)$ and post-LT $(n=241)$ patients with lamivudine -resistance who were treated for medians of 39 and 99 weeks, respectively [19]. After 96 weeks, HBV DNA levels were undetectable in $65 \%$ of wait-listed and post-LT patients. $91 \%$ of patients classified as CPS B or C at baseline had an improvement of at least one point in their score at 48 weeks. $32(14 \%)$ deaths were reported in the wait-listed group or within 30 days of their last dose of study drug. However, Kaplan-Meier estimates of survival for wait-listed patients were $86 \%$ at week 45 and $78 \%$ by week 96 . Furthermore, out of 100 patients surveyed, 57 did not undergo LT of whom 21 were removed from the list due to marked clinical improvement. The Kaplan-Meier estimate of post-LT survival in patients treated with adefovir was $87 \%$ at three years compared to $44 \%$ at the same interval if antivirals were not prescribed. An interesting observation of this study was that among wait-listed patients who underwent LT, prevention against graft reinfection was similar between patients who received and did not received HBIG over a 35 week period. Surprisingly, HbsAg was detected less frequently in patients who did not receive $\mathrm{HBIG}-\mathrm{it}$ was present in $6 \%$ who received and $0 \%$ who did not received HBIG, respectively.

Nephrotoxicity remains an important although uncommon side effect of adefovir yet it was a cause of treatment discontinuation in $4 \%$ of patients, usually in those with underlying hepatorenal syndrome. Adefovir resistance was present in only $2 \%$ of patients after a follow-up of 144 weeks with the only resistance mutation noted in domain $\mathrm{D}$ of the polymerase/reverse transcriptase gene. However, it appears that the addition of adefovir to lamivudine rather than drug substitution would be the preferred intervention for the management of lamivudine-resistant HBV although where possible, sequence analysis of the polymerase/reverse transcriptase gene should be performed to better guide therapy rather than using rising viral loads or aminotransferases as surrogate markers of drug resistance $[20,21]$.

\section{Newer Nucleoside/Nucleotide Antivirals}

Entecavir, tenofovir and telbivudine are some of the latest antivirals being used in patients with chronic HBV although experience is limited in patients with decompensated cirrhosis. A variety of studies are being conducted to assess their safety and efficacy in this group of patients. Preliminary reports are encouraging with case reports and studies strongly supporting a role for introduction of these newer agents in patients with lamivudine and /or adefovir-resistance [22, 23].

\section{Entecavir}

Entecavir is a nucleoside analogue which inhibits viral polymerase activity and both minus and plus strand DNA synthesis. It has potent anti-viral activity and leads to a profound decrease in viral load in both HbeAg-positive and negative patients [24, 25]. The incidence of entecavir resistance also remains low in naïve patients even after four years of treatment but despite these encouraging findings, HbeAg seroconversion remains low and comparable to that observed with other nucleoside analogues [26, 27]. However, when entecavir is administered to patients with lamivudine resistance, entecavir-resistant mutations develop in at least $35 \%$ of patients after four years [28]. Current data suggests that entecavir resistance follows a 'two-hit' model with primary resistance occurring at position $\mathrm{rt} 204$ followed by secondary mutations at positions rt184, rt 202 or $\mathrm{rt} 250$ leading to higher entecavir resistance [29]. Although lamivudine- resistant strains exhibit intermediate sensitivity to entecavir, this only occurs when entecavir is administered at a higher dose of one milligram per day. Once secondary mutations develop, entecavir resistance occurs followed by viral breakthrough and the only other options for treatment are to add adefovir or tenofovir. This suggests that entecavir should not be administered to lamivudine-resistant patients but may be a better option for nucleoside-naive patients. 


\section{Tenofovir}

Tenofovir is a purine nucleotide analog and exhibits potent inhibitory activity against a wild type and drugresistant mutants such as lamivudine and entecavir resistant strains. Tenofovir has been used mainly in HIV-HBV coinfected patients as tenofovir is also active against HIV reverse transcriptase. Although experience with tenofovir is limited in patients with chronic HBV, two recent studies comparing tenofovir $300 \mathrm{mg}$ per day versus adefovir $10 \mathrm{mg}$ per day eAg-negative and -positive patients, respectively, were recently published [30]. The authors reported that viral suppression occurred in more $\mathrm{HbeAg}$-negative patients receiving tenfovir than adefovir $(93 \%$ versus $63 \%, p<$ $0.001)$. No mutations of HBV DNA polymerase associated with tenofovir resistance were noted and the HBV DNA response to tenofovir was similar in patients regardless of whether they had been exposed to lamivudine. However, the rate of HbeAg seroconversion was comparable to other nucleoside analogues. Due to its spectrum of activity, tenofovir appears to have a role in both naïve patients and in those with first-line treatment failure particularly as in vivo evidence suggests it is active against lamivudine, entecavir, adefovir and telbivudine resistant mutants.

\section{Telbivudine}

Telbivudine is a nucleoside analogue with strong antiviral effects comparable to entecavir in clinical trials on $\mathrm{HBeAg}$-positive and negative patients [31, 32]. Although the rate of HbeAg seroconversion is comparable to lamivudine and entecavir, telbivudine administration is associated with a resistance rate of approximately $10 \%$ per year. Telbivudine selects for the rt M204I mutation which also confers resistance to lamivudine and entecavir but is sensitive to adefovir and tenofovir. Although telbivudine can be used for nucleoside naïve patients and patients with adefovir resistant strains, the lower rates of viral resistance observed with entecavir and tenofovir will probably lead to restricted use of telbivudine. Although it remains to be seen whether a combination of anti-virals or the sequential addition of these medications would be best for suppressing viral load and clinical status prior to LT, clinicians need to be cognizant that most deaths in these patients occur within the first six months of treatment, reflecting the severity of their underlying liver disease [15].

\section{USE OF HEPATITIS B POSITIVE DONORS}

Due to the persistent shortage of donors for LT, the use of HBV- positive donors has been utilized in selected recipients since the mid-1990's. A number of studies have reported that core antibody donors should not be used in naïve recipients due to an extremely high risk of transmitting HBV to the recipients, regardless of the donor's surface antibody status [33]. Core antibody donors may be used safely in surface antibody recipients as the risk of $\mathrm{HBV}$ transmission is negligible but when used in core antibody recipients who are surface antibody negative, the risk of acquiring HBV is at least $13 \%$ (Table 1). However, a recent case series reported that one out of four recipients who were core and surface antibody positive became HBsAg positive four years after each had received a core antibody positive living graft and lamivudine prophylaxis [34]. Further investigations in this patient demonstrated the HBsAb titer was less than $10 \mathrm{IU} / \mathrm{L}$ whereas the other patients had titers greater than this. Patients who receive hepatitis B donors and are at high risk of acquiring HBV should be treated with anti-virals and HBIG although the combination and duration of therapy varies between transplant centers [35, 36]. Recently, a study based on 89 liver transplant programs worldwide reported that all programs used nucleos(t)ide therapy in core antibody recipients of core antibody donors [37]. However, lamivudine was used the greatest $(58 \%$ for US physicians and $81 \%$ for non-US physicians) and HBIG was used most frequently in the US (69\% versus $46 \%, P=$ 0.03). Although $81 \%$ of physicians used nucleos(t)ide therapy indefinitely, the duration and method of administration of HBIG varied widely.

\section{PREVENTION AND TREATMENT OF RECURRENT HEPATITIS B AFTER LIVER TRANSPLANTATION}

The initial results of LT for HBV were very poor due to universal recurrence of $\mathrm{HBV}$ leading to early graft loss and very poor patient survival [38-40]. However, the introduction of intravenous HBIG in the early 1990's was a breakthrough in the management of these patients for although graft infection was not always prevented, at least it was delayed which led to improved patient and graft survival $[41,42]$. With experience, it became evident that a variety of factors influenced the recurrence rate of HBV such as pre-LT HBV DNA viral load, duration of HBIG therapy and trough surface antibody levels. For example, HBV recurrence rates were very low in patients transplanted with ALF or hepatitis delta co-infection as HBV DNA levels are usually undetectable or very low, respectively in these conditions. (However, many patients with low or undetectable viral loads from these early studies would have positive levels now due to the development of more sensitive quantitative assays).

Table 1. Risk of Hepatitis B Transmission in Recipients of Hepatitis B Core Anti-Body Donors [29]

\begin{tabular}{|l|l|}
\hline \multicolumn{1}{|c|}{ Donor Hepatitis B Status } & Recipient Hepatitis B Status and Risk of Acquiring Hepatitis B \\
\hline \hline Surface antibody positive & HBV naïve - 0\% developed HBV \\
\hline Core antibody positive & $\begin{array}{l}\text { HBV naïve- } 72 \%(18 / 25) \text { developed HBV, regardless of donor's surface antibody status; } 4 \text { of the } 18 \text { patients } \\
\text { received surface positive and core positive donors }\end{array}$ \\
\hline Surface and core antibody positive & HBV naïve-high risk of acquiring HBV (see above) \\
\hline Core antibody positive & Surface antibody positive - $0 \%$ developed HBV \\
\hline Core antibody positive & Core antibody positive - $13 \%$ developed HBV \\
\hline
\end{tabular}


The use of lamivudine monotherapy to prevent recurrence also showed promise at one year with reinfection rates as low as $10 \%$ but at three years, HBV recurred in nearly $50 \%$ of patients [43]. This was not a surprising figure as high resistance rates are commonly observed in nontransplant patients and, as observed in patients receiving HBIG monotherapy, the risk of recurrence was greatest in patients with high HBV DNA levels at the time of LT. As HBIG and lamivudine work by different mechanisms, the combination of these two agents has been used as the standard of care for the prevention of HBV recurrence postLT with recurrence rates ranging between $0-11 \%$ [44, 45]. However, treatment has not been standardized, particularly with the use of HBIG with some centers aiming for titers greater than $100 \mathrm{IU} / \mathrm{L}$ for the first six months while others aim for higher levels or use either fixed or variable dosing [46-50]. Regardless of the dose or frequency of intravenous HBIG therapy, all these combinations are highly effective regardless of pre-transplant viral load (Tables $\mathbf{2 , 3}$ ).

There remain several concerns with the use of long-term lamivudine and intravenous $\mathrm{HBIG}$ for liver transplant recipients with $\mathrm{HBV}$. As previously reported, the risk of lamivudine resistance increases with the duration of treatment which can not only precipitate progressive liver injury and graft loss but several studies have also reported and increased rate of $\mathrm{HBV}$ recurrence in patients with lamivudine resistance at the time of LT [46]. Intravenous HBIG remains a prohibitively expensive medication with

Table 2. High Dose HBIG and Lamivudine for Post-Transplant Hepatitis B

\begin{tabular}{|c|c|c|c|c|c|c|}
\hline References & $\begin{array}{l}\text { Patients } \\
\text { (n) }\end{array}$ & $\begin{array}{c}\text { Antiviral } \\
\text { Pre-LT (\%) }\end{array}$ & $\begin{array}{l}\text { DNA+ at } \\
\text { LT(\%) }\end{array}$ & HBIG Protocol & $\begin{array}{l}\text { Follow-Up } \\
\text { (Months) }\end{array}$ & Recurrence (\%) \\
\hline Markowitx et al. [39] & 14 & 36 & 7 & $\begin{array}{l}\text { Up to } 100,000 \mathrm{IU} \text { for } 1 \text { month; then } \\
10,000 \mathrm{IU} / \text { month }\end{array}$ & 12.7 & 0 \\
\hline Han et al. [40] & 59 & 34 & 27 & $\begin{array}{c}80,000 \mathrm{IU} \text { in } 1^{\text {st }} \text { month; then } 10,000 \\
\mathrm{IU} / \text { month }\end{array}$ & 15 & 0 \\
\hline Marzano et al. [41] & 26 & 100 & 27 & $\begin{array}{l}\text { 46,500 IU first month; then } 5000 \\
\text { IU/month }\end{array}$ & 30 & 4 \\
\hline Rosenau et al. [42] & 21 & 52 & 24 & $\begin{array}{c}40,000 \mathrm{IU} 1 \mathrm{stwk} \text {; aim for titer }> \\
500 \mathrm{IU} / \mathrm{L} \text { for } 1 \mathrm{wk} \text { and then }>100 \mathrm{IU} / \mathrm{L}\end{array}$ & 21 & $\begin{array}{l}9.5 \text { (all lamivudine } \\
\text { resistant pre-LT) }\end{array}$ \\
\hline Rosenau et al. [38] & 19 & 100 & 47 & $\begin{array}{l}10,000 \mathrm{IU} / \text { day until titer }>1000 \mathrm{IU} / \mathrm{L} \\
\text { then aim for titer }>100 \mathrm{IU} / \mathrm{L}\end{array}$ & NA & $\begin{array}{c}20 \text { (all lamivudine resistant } \\
\text { pre-LT) }\end{array}$ \\
\hline Seehofer et al. [43] & 17 & 100 & 29 & $\begin{array}{l}80,000 \mathrm{IU} \text { for } 1 \text { month; then aim for } \\
\text { titer }>100 \mathrm{IU} / \mathrm{L}\end{array}$ & 25 & $\begin{array}{l}\text { 18( all lamivudine resistant } \\
\text { pre-LT }\end{array}$ \\
\hline Steinmuller et al. [44] & 51 & 100 & NA & $\begin{array}{l}10,000 \mathrm{IU} / \text { day until sAg cleared; then } \\
\text { aim for titer }>100 \mathrm{IU} / \mathrm{L}\end{array}$ & 35 & $\begin{array}{l}8 \text { (3 out of } 4 \text { lamivudine } \\
\text { resistant pre-LT }\end{array}$ \\
\hline
\end{tabular}

Key: HBIG hepatitis B immune globulin; LT liver transplantation; IU/L international units per liter; NA not available; sAg hepatitis B virus surface antigen.

Table 3. Low Dose HBIG and Lamivudine in Management of Post-Transplant Hepatitis B

\begin{tabular}{|c|c|c|c|c|c|c|}
\hline References & Patients (n) & Antiviral pre-LT (\%) & DNA+ at LT (\%) & HBIG Protocol & Follow-Up (Months) & Recurrence (\%) \\
\hline Angus et al. & 32 & 97 & NA & $\begin{array}{l}800 \mathrm{IU} \text { im at } \mathrm{LT} \\
\text { and daily for } 1 \\
\text { week; } 800 \mathrm{IU} \text { im } \\
\text { monthly }\end{array}$ & 18.4 & 3.1 \\
\hline Ferretti et al. & 23 & 48 & 13 & $\begin{array}{l}80,000 \mathrm{IU} \text { iv in } 1 \mathrm{st} \\
w \mathrm{k} ; 1200 \mathrm{IU} \text { im to } \\
\text { keep titre }>100 \mathrm{IU} / \mathrm{L}\end{array}$ & 20 & 3.6 \\
\hline Karademir et al. & 35 & 51 & 14 & $\begin{array}{l}4000 \mathrm{IU} \text { im at } \\
\mathrm{LT} ; 2000 \mathrm{IU} \text { daily } \\
\text { until titer }>200 \\
\mathrm{IU} / \mathrm{L} \text { and then aim } \\
\text { for } 100 \mathrm{IU} / \mathrm{L}\end{array}$ & 16 & $\begin{array}{c}5.7 \text { (all were } \\
\text { lamivudine resistant } \\
\text { pre-LT) }\end{array}$ \\
\hline Zheng et al. & 114 & $\begin{array}{l}\text { NA (lamivudine in } 99 \\
\text { post-LT) }\end{array}$ & 31 & $\begin{array}{l}2000 \mathrm{IU} \text { im at } \\
\mathrm{LT} ; 800 \mathrm{IU} \text { im daily } \\
\text { for } 6 \text { days, weekly } \\
\text { for } 3 \text { weeks and } \\
\text { then montly }\end{array}$ & 15.8 & 14 \\
\hline Gane et al. & 147 & 85 & $<50$ & $\begin{array}{l}800 \mathrm{IU} \text { im at LT } \\
\text { and daily for } 6 \\
\text { days;then } 800 \mathrm{IU} \\
\text { im monthly }\end{array}$ & 61 & 4 \\
\hline
\end{tabular}


fixed dosing costing at least $\$ 100,000$ in the first post-LT year and at least $\$ 50,000$ in subsequent years [51]. The development of intramuscular HBIG and new and more potent nucleoside/nucleotide inhibitors has transformed the management of post-LT HBV [52-58]. However, in parallel with the development of new anti-virals for HBV, several studies have recently been performed to determine the most cost-effective regimen for HBV prevention post-LT [59]. Recently, Saab et al. performed a decision analysis comparing costs and outcomes of two strategies for HBV prophylaxis one year after LT [60]. The first strategy consisted of prophylaxis with lamivudine and adefovir while the second consisted of intramuscular HBIG and lamivudine with the addition of adefovir in patients who subsequently developed HBV recurrence. Patients who failed with adefovir and lamivudine were then treated with tenofovir and entecavir. $16.8 \%$ of liver transplant recipients had HBV recurrence after 10 years of treatment with lamivudine and HBIG. The medical costs for strategy 1 and 2 after 10 years of therapy were $\$ 151,819$ and $\$ 166,246$, respectively, and this resulted in cost savings of $\$ 14,427$. A one way sensitivity analysis demonstrated that the model was most sensitive to cost changes of adefovir and HBIG as well as HBV recurrence but robust to costs of lamivudine, laboratory costs, administrative fees, and office visit fees. This decision analysis model resulted in marked savings in costs with strategy one providing pharmacoeconomic support for the use of this strategy as first-line therapy in HBV prophylaxis in liver transplant recipients one year after liver transplantation.

Several studies have also reported encouraging results with nucleoside/nucleotide monotherapy after combination treatment with HBIG for 1 year and it seems monotherapy with a nucleoside/nucleotide inhibitor will be a real possibility in the near future. For example, a single center study by Nath et al. on 32 patients with HBV (77\% were coinfected with $\mathrm{HCV}$ ) has yielded promising results-the investigators limited HBIG to the first week post-LT and used lamivudine and adefovir if HBV DNA levels were greater than $10000 \mathrm{IU} / \mathrm{ml}$, reserving adefovir monotherapy for lower levels [61]. The authors reported $100 \%$ patient and graft survival at two year follow up with all patients except one having normal liver tests- the one patient who developed re-infection was transplanted one day after starting anti-viral therapy. In a recent randomized study, 34 patients receiving low dose intramuscular HBIG and lamivudine prophylaxis for at least 12 months were randomized to lamivudine and adefovir combination therapy while the remaining patients were maintained on HBIG and lamivudine [62]. At 21 months follow-up, no patient from either group had disease recurrence and all remained HBV DNA negative although one patient from the lamivudine/adefovir arm had a low titer of $\mathrm{HbsAg}$ in serum. Although median creatinine did not change significantly in both groups, one patient in the adefovir group with a history of diabetic and hypertensive nephropathy developed a rising creatinine that led to adefovir cessation at 15 months. The annual cost of adefovir and lamivudine combination therapy was $\$ 8,290$ versus $\$ 13,718$ for HBIG and lamivudine. Thus this change in therapy not only produced significant cost savings and improvement in quality of life but also had no deleterious impact on HBV recurrence.
The development of new potent oral nucleosid(t)es for HBV has not only expanded the therapeutic armamentarium for HBV treatment but also provided an opportunity to greatly modify our strategies for preventing and treating HBV recurrence [63]. As these drugs appear to have altered the natural history of HBV by leading to clinical stabilization and even reversal of decompensated cirrhosis, the number of patients transplanted for HBV-related liver failure is falling as they are more likely to be transplanted for HCC.

Clinical experience in the post-LT setting has been greatest with adefovir and entecavir which are gradually replacing lamivudine - studies on the other new agents are currently in progress. In transplant patients, entecavir appears to be more potent than adefovir with based on intermediate-term studies in the non-transplant population that have reported entecavir resistance in only $1 \%$ of patients after three to four years of continuous treatment $[64,65]$. In contrast, several studies have reported considerably higher rates of adefovir resistance with nonresponse rates of at least $25 \%$ to the standard dose of $10 \mathrm{mg}$ per day [66]. However, drug resistance and non-response to adefovir is extremely uncommon when adefovir is combined with lamivudine although cost-effectiveness studies comparing this combination with newer nucleosides/nucleotides have yet to be conducted. Although Schiff et al. also reported that adefovir monotherapy was effective in preventing HBV recurrence in the presence of lamivudine resistance post-LT, the investigators did not report the percentage of patients who received lamivudine/adefovir therapy versus adefovir monotherapy [19]. Due to entecavir's modest activity and high rates of viral resistance in the presence of lamivudine resistance in non-transplant patients, entecavir is usually not recommended for use in lamivudine-resistant liver transplant recipients with HBV.

Studies evaluating nucleosid(t)e therapy without HBIG may also be valuable in countries where HBIG is unavailable due to financial constraints. Recently, a seven year follow up study was reported by investigators from Hong Kong on 24 patients treated with lamivudine prophylaxis until drug resistance developed in seven patients leading to the addition of adefovir [67]. Although HBV DNA levels were too low for sequencing in three patients, four patients had the rtM204I mutation characteristic of lamivudine resistance. After a mean follow up of 150 weeks, HBV DNA was undetectable in $29 \%$ of patients, between $10-100$ copies $/ \mathrm{ml}$ in another $29 \%$ and between $10,000-100,000$ copies $/ \mathrm{ml}$ in $43 \%$ of patients. No resistance to adefovir was noted suggesting that lamivudine as monoprophylaxis followed by adefovir salvage clearly has an important role in post-LT HBV prophylaxis.

\section{OUTCOMES OF LIVER TRANSPLANTATION FOR HBV}

A retrospective review of the UNOS database between 1993 and 2004 reported that of 53,312 LT's performed in the United States, 2314 (4.34\%) were for HBV [68]. Patients coinfected with hepatitis $\mathrm{C}$ were excluded from the analysis. 1816 cases $(78 \%)$ were due to chronic HBV infection and 498 cases (22\%) were due to HBV-related ALF. Interestingly, the investigators reported that three and five year survival rates for patients transplanted for chronic HBV 


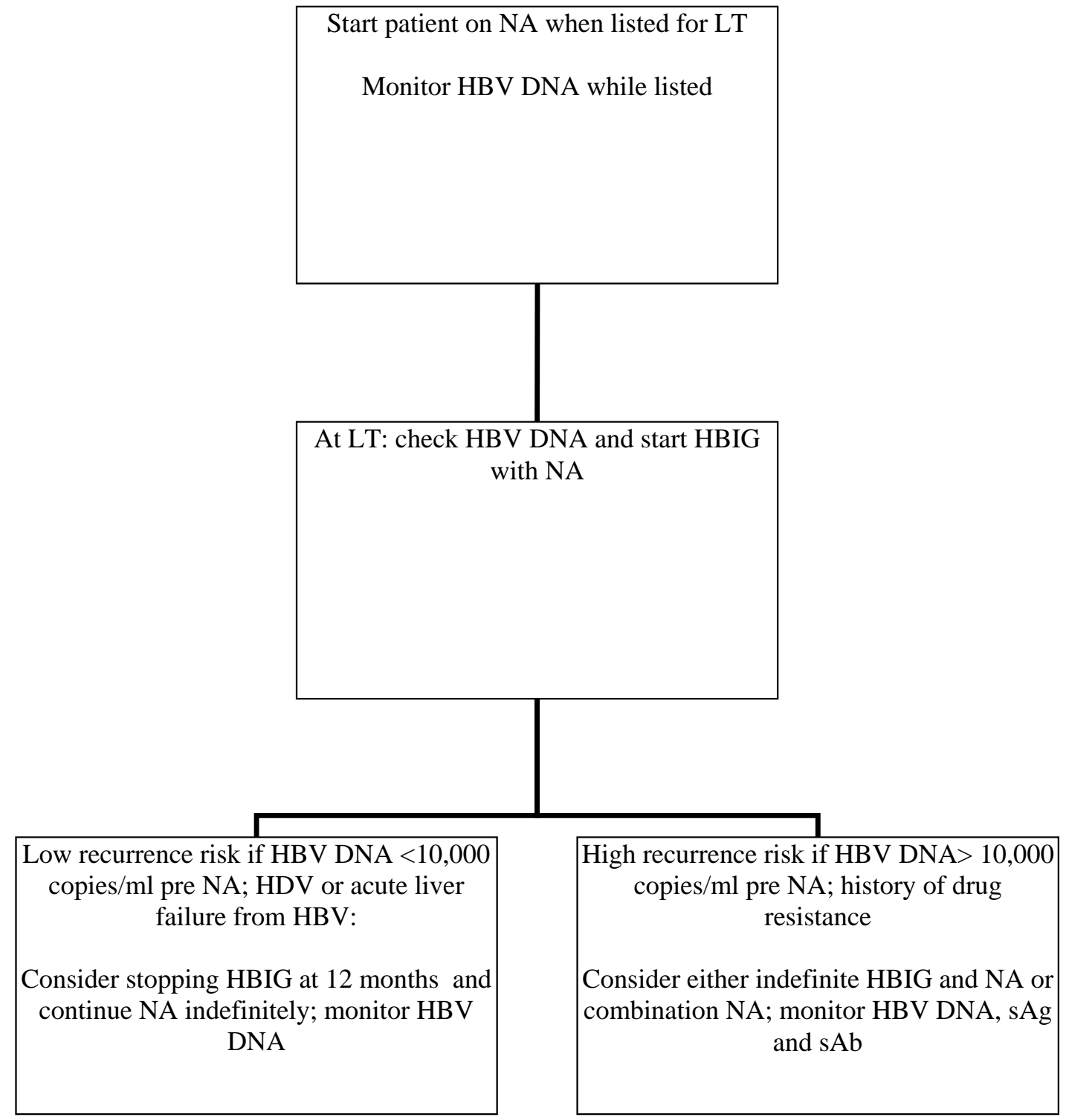

Key: HBIG hepatitis B immune globulin; HBV hepatitis B virus; HDV hepatitis delta virus; sAb hepatitis B surface antibody; sAg hepatitis B surface antigen; LT liver transplantation; NA nucleoside/nucleotide analogue.

Fig. (1). Suggested algorithm for flowchart for HBV prophylaxis using HBIG and nucleosides/nucleotides.

were better compared to patients transplanted for ALF from HBV or other liver -transplant recipients. However, there were important imitations of this study. For example, only data from five states was analyzed as they historically received large numbers of immigrants from HBV endemic areas. In addition, the authors also did not report the percentage of patients transplanted for $\mathrm{HCC}$ related to underlying $\mathrm{HBV}$ nor the impact of post-transplant HBV treatment on outcomes. An additional retrospective study of 104 patients from Europe reported 5 year patient and graft survival rates of $80 \%$ and $73 \%$, respectively [69]. In multivariate analysis, factors associated with poor patient survival were advanced recipient age, high body mass index, cyclosporine-based immuosuppression and increased cold ischemia time. Risk factors for graft cirrhosis included viremia greater than 10 copies $/ \mathrm{ml}$, nucleos $(\mathrm{t})$ ide prophylaxis without HBIG, mycophenolate mofetil use for less than one year and biliary tract complications.

To address the impact of HBIG and oral anti-virals on outcomes of post-transplant HBV, investigators from the Mayo clinic analyzed survival of LT recipients with HBV in the United States over the last 15 years to examine the effect of these innovations [70]. This retrospective analysis was conducted based on data collected prospectively by UNOS in all adult (older than 18) patients undergoing primary LT in the United States between 1987 and 2002. Patients were divided into three groups: era 1 (1987-1991), era 2 (19921996), and era 3 (1997-2002). Era 1 consisted of 6,708 patients (675 with HBV), era 2 consisted of 13,995 patients (1,005 with HBV), and era 3 consisted of 20,730 patients (1,723 with HBV). An important observation of patients from era 3 was that they were older and had less advanced liver disease and shorter ischemic time during LT. The 
survival of patients with HBV was significantly better for era 2 than for era $1(P<0.01)$ and for era 3 than for Era $2(P<$ $0.01)$. Unlike previous reports, fulminant disease and Asian race had no effect on patient survival. The authors concluded that the data underscored the effectiveness of therapeutic innovations over the past two decades and reflected the timely and widespread adoption of these measures by transplant centers nationally.

\section{SUMMARY}

Transplant physicians will need to be well-versed with the new generation of anti-HBV medications, particularly as HBIG may play a lesser role and be confined only to the early post-LT period. Anti-viral monotherapy with vigilant monitoring for drug resistance appears to be the most-costeffective approach to the management of these patients, particularly in health care systems which do not use HBIG due to its prohibitive cost, and hopefully data from welldesigned randomized studies will guide transplant physicians in the care of these patients [71]. Until the results of these studies are available, one reasonable strategy is to treat waitlisted patients with oral anti-virals in an attempt to render them HBV DNA. At the time of LT, HBV DNA levels should be repeated in order to stratify them into a low versus high recurrence group (Fig. 1). HBIG should be initiated at LT and continued with oral antivirals for at least twelve months at which point HBIG may be discontinued in low risk groups while oral agents indefinitely continued in parallel with frequent monitoring of liver function tests, HBV DNA and HBV markers. Patients at high risk of recurrence should be maintained on HBIG and oral agents indefinitely together with frequent monitoring of liver function tests, HBV DNA and HBV markers. However, this recommendation will undoubtedly evolve as it is likely the newer generation of more potent oral anti-virals may minimize or even obviate the need for HBIG in carefully selected patients [72]. However, unless restricted by limited health care resources, transplant physicians should strive to practice evidence-based medicine and resist the temptation to use these medications ad hoc until data from prospective randomized studies and the appropriate economic analyses confirm these hypotheses.

\section{REFERENCES}

[1] Lavanchy D. Hepatitis B virus epidemiology, disease burden, treatment and current and emerging prevention and control measures. J Viral Hepat 2004; 11: 97-107.

[2] Kim WR. Epidemiology of hepatitis B in the United States. Hepatology 2009; 49: S28-34.

[3] Kim WR, Terrault NA, Pedersen RA, et al. Trends in waitlist registration for liver transplantation for viral hepatitis in the US. Gastroenterology 2009; 137: 1680-6.

[4] Pungapong S, Kim WR, Poterucha JJ. Natural history of hepatitis B virus infection: an update for clinicians. Mayo Clin Proc 2007; 82: $967-$ 75.

[5] Hoofnagle JH. Reactivation of hepatitis B. Hepatology 2009; 49 (5 Suppl): S156-65.

[6] Loomba R, Rowley A, Wesley R, et al. Systematic review: the effect of preventive lamivudine on hepatitis B reactivation during chemotherapy. Ann Intern Med 2008; 148: 519-28.

[7] Palmore TN, Shah NL, Loomba R, et al. Reactivation of hepatitis B with reappearance of hepatitis $B$ surface antigen after chemotherapy and immune suppression. Clin Gastroenterol Hepatol 2009; 7: 1130-7.

[8] European Association for the Study of Liver. EASL Clinical practice guidelines: Management of chronic hepatitis B. J Hepatol 2009; 50: $227-42$.
[9] Terrault NA. Benefits and risks of combination therapy for hepatitis B. Hepatology 2009; 49 (5 Suppl): S122-8.

[10] Sorrell MF, Belongia EA, Costa J, et al. National Institutes of Health Consensus Development Conference Statement: management of hepatitis B. Ann Intern Med 2009; 150: 104-10.

[11] Keeffe EB, Dieterich DT, Han SH, et al. Treatment algorithm for the management of chronic hepatitis B virus infection in the United States: 2008 update. Clin Gastroenterol Hepatol 2008; 6: 1315-41.

[12] Papatheodoridis GV, Cholongitas E, Archimandritis AJ, Burroughs AK. Current management of hepatitis B virus infection before and after liver transplantation. Liver Int 2009; 29: 1294-305.

[13] Dienstag JL. Hepatitis B virus infection. N Engl J Med 2008; 359: 1486-500.

[14] Perrillo RP, Wright T, Rakela J, et al. Lamivudine North American Transplant Group. A multicenter United States - Canadian trial to assess lamivudine monotherapy before and after liver transplantation. Hepatology 2001; 33: 424-32.

[15] Fontana RJ, Hann HW, Perrillo RP, et al. Determinants of early mortality on patients with decompensated chronic hepatitis B treated with antiviral therapy. Gastroenterology 2002; 123: 719-27.

[16] Grellier L, Multimer D, Ahmed M, et al. Lamivudine prophylaxis against reinfection in liver transplantation for hepatitis $\mathrm{B}$ cirrhosis. Lancet 1996; 348: 1212-15.

[17] Perillo R, Rakela J, Dienstag J, et al. Multicenter study of lamivudine therapy for hepatitis B after liver transplantation. Lamivudine Transplant Group. Hepatology 1999; 29: 1581-86.

[18] Schiff ER, Lai CL, Hadziyannis S, et al. Adefovir dipivoxil therapy for lamivudine-resistant hepatitis B in pre-and post-liver transplantation patients. Hepatology 2003; 38: 1419-27.

[19] Schiff E, Lai CL, Hadziyannis S, et al. Adefovir dipivoxil for waitlisted and post-liver transplantation patients with lamivudine-resistant hepatitis B: final long-term results. Liver Transpl 2007; 13: 349-60.

[20] Villeneuve JP, Durantel D, Durantel S, et al. Selection of a hepatitis B virus strain resistant to adefovir in a liver transplantation patient. J Hepatol 2003; 39: 1085-9.

[21] Villet S, Pichoud C, Villeneuve JP, Trépo C, Zoulim F. Selection of a multiple -resistant hepatitis B virus strain in a liver transplanted patient. Gastroenterology 2006; 131: 1253-61.

[22] Ratziu V, Thibault V, Benhamou Y, Poynard T. Successful rescue therapy with tenofovir in a patient with hepatic decompensation and adefovir resistant HBV mutant. Comp Hepatol 2006; 5: 1.

[23] Choe WH, Kwon SY, Kim BK, et al. Tenofovir plus lamivudine as rescue therapy for adefovir-resistant chronic hepatitis $\mathrm{B}$ in hepatitis $\mathrm{B}$ e antigen-positive patients. Liver Int 2008; 28: 814-20.

[24] Chang TT, Gish RG, de Man R, et al. A comparison of entecavir and lamivudine for $\mathrm{HBe} \mathrm{Ag}$-positive chronic hepatitis B. N Engl J Med 2006; 354: 1001-10.

[25] Lai CL, Shouval D, Lok AS, et al. Entecavir versus lamivudine for patients with HBe Ag-negative chronic hepatitis B. N Engl J Med 2006; 354: 1011-20.

[26] Colonno RJ, Rose R, Baldick CJ, et al. Entecavir resistance is rare in nucleoside naïve patients with hepatitis B. Hepatology 2006; 44: 165665 .

[27] Sherman M, Yurdaydin C, Sollano J, et al. Entecavir for treatment of lamivudine-refractory $\mathrm{HBeAg-positive} \mathrm{chronic} \mathrm{hepatitis} \mathrm{B.}$ Gastroenterology 2006; 130: 2039-49.

[28] Tenney DJ, Rose RE, Baldick CJ, et al. Two year assessment of entecavir resistance in lamivudine-refractory hepatitis B patients reveals different clinical outcomes depending on the resistance substitution present. Antimicrob Agents Chemother 2007; 51: 902-11.

[29] Villet S, Ollivet A, Pichoud C, et al. Stepwise process for the development of enetecavir resistanace in a chronic hepatitis B virusinfected patients. J Hepatol 2007; 46: 531-8.

[30] Marcellin P, Jenny Heathcoate E, Buti M, et al. Tenofovir disoproxil fumarate versus adefovir dipivoxil for chronic hepatitis B. N Engl J Med 2008; 359: 2442-55.

[31] Lai CL, Leung N, Teo EK, et al. A 1 year trial of telbivudine, lamivudine and the combination in patients with hepatitis $\mathrm{B}$ e antigen positive chronic hepatitis B. Gastroenterology 2005; 129: 528-36.

[32] Lai CL, Gane E, Liaw YF, et al. Telbivudine versus lamivudine in patients with chronic hepatitis B. N Engl J Med 2007; 357: 2576-88.

[33] Dodson SF, Issa S, Araya V, et al. Infectivity of hepatic allografts with antibodies to hepatitis B virus. Transplantation 1997; 64: 1582-4.

[34] Ikegami T, Taketomi A, Ohta R, et al. The risks of HBV infection after liver transplantation from $\mathrm{HBc}$ antibody positive donor to the $\mathrm{HBs}$ antibody recipient. Hepatogastroenterology 2008; 55: 2162-5. 
[35] Dodson SF, Issa S, Araya V, et al. Antibodies to hepatitis B surface antigen prevents reactivation in recipients of liver grafts from anti-Hb core anti-HB c positive donors. Gut 2002; 50: 95-9.

[36] Holt D, Thomas R, Van Thiel D, Brems JJ. Use of hepatitis B core antibody-positive donors in orthotopic liver transplantation. Arch Surg 2002; 137: 572-5

[37] Perrillo R. Hepatitis B virus prevention strategies for antibody to hepatitis $\mathrm{B}$ core antigen positive liver donation: a survey of North American, European and Asian-Pacific transplant programs. Liver Transpl 2009; 15: 223-32.

[38] Davies SE, Portmann BC, O'Grady JG, et al. Hepatic histological findings after transplantation for chronic hepatitis B virus infection, including a unique pattern of fibrosing cholestatic hepatitis. Hepatology $1991 ; 13: 150-7$

[39] Todo S, Demetris AJ, Van Thiel D, Teperman L, Fung JJ, Starzl TE. Orthotopic liver transplantation for hepatitis B-virus related liver disease. Hepatology 1991; 13: 619-26.

[40] O'Grady JG, Smith HM, Davies SE, et al. Hepatitis B virus infection after orthotopic liver transplantation. Serological and clinical implications. J Hepatol 1992; 14: 104-11.

[41] Muller R, Gubernatis G, Farle M, et al. Liver transplantation in hepatitis $\mathrm{B}$ surface antigen carriers. Prevention of hepatitis B virus recurrence by passive immunization. J Hepatol 1991; 13: 90-96.

[42] Samuel D, Muller R, Alexander G, et al. Liver transplantation in European patients with the hepatitis B surface antigen. N Engl J Med 1993; 329: 1842-47.

[43] Mutimer D, Pillay D, Dragon E, et al. High pre-treatment serum hepatitis $\mathrm{B}$ virus titre predicts failure of lamivudine prophylaxis and graft re-infection after liver transplantation. J Hepatol 1999; 30: 715-21.

[44] Rosenau J, Bahr MJ, Tillmann HL, et al. Lamivudine and low-dose hepatitis B immune globulin for prophylaxis of hepatitis B reinfection after liver transplantation: possible role of mutations in the YMDD motif prior to liver transplantation as a risk factor for reinfection. $\mathrm{J}$ Hepatol 2001; 34: 895-902.

[45] Marzano A, Salizzoni M, Debernadi-Vernon W, et al. Prevention of hepatitis B virus recurrence after liver transplantation in cirrhotic patients treated with lamivudine and passive immunoprophylaxis. J Hepatol 2001; 34: 903-10.

[46] Seehofer D, Rayes N, Naumann U, et al. Preoperative antiviral treatment and postoperative prophylaxis in HBV-DNA positive patients undergoing liver transplantation. Transplantation 2001; 72: 1381-85.

[47] Markowitz JS, Martin P, Conrad AJ, et al. Prophylaxis against hepatitis $\mathrm{B}$ recurrence following liver transplantation using combination lamivudine and hepatitis B immune globulin. Hepatology 1998; 28: $585-9$.

[48] Han SH, Ofman J, Holt C, et al. An efficacy and cost-effectiveness analysisof combination hepatitis $\mathrm{B}$ immune globulin and lamivudine to prevent recurrent hepatitis $\mathrm{B}$ after orthotopic liver transplantation compared with hepatitis B immune globulin monotherapy. Liver Transpl 2000; 6: 741-8.

[49] Rosenau J, Bahr MJ, Tilmann HL, et al. Lamivudine and low-dose hepatitis B immune globulin for prophylaxis of hepatitis B reinfection after liver transplantation: possible role of mutations in the YMDD motif prior to transplantation as a risk factor for reinfection. J Hepatol 2001; 34: 895-902.

[50] Steinmuller T, Seehofer D, Rayes N, et al. Increasing applicability of liver transplantation for patients with hepatitis B- related liver disease. Hepatology 2002; 35: 1528-35.

[51] Dan Y, Wai C, Yeoh K, Lim S. Prophylactic strategies for hepatitis B patients undergoing liver transplant: a cost-effectiveness analysis. Liver Transpl 2006; 12: 736-46.

[52] Anderson RD, Chinnakotla S, Guo L, Perrillo RP, Klintmalm GB, Davis GL. Intramuscular hepatitis B immunoglobulin and nucleosides for prevention of recurrent hepatitis B following liver transplantation: comparison with other HBIG regimens. Clin Transplant 2007; 21: 5107.

[53] Gane EJ, Angus PW, Strasser S, et al. Lamivudine plus low dose hepatitis B immunoglobulin to prevent recurrent hepatitis B following liver transplantation. Gastroenterology 2007; 132: 931-7.

[54] Angus PW, Patterson SJ, Strasser SI, McCaughan GW, Gane E. A randomized study of adefovir dipoxil in place of HBIG in combination with lamivudine as post-liver transplantation hepatitis B prophylaxis. Hepatology 2008; 48: 1460-6.

[55] Angus PW, McCaughan GW, Gane EJ, Crawford DH, Harley H. Combination low-dose hepatitis B immune globulin and lamivudine therapy provides effective prophylaxis against posttransplantation hepatitis B. Liver Transpl 2000; 6: 429-33

[56] Ferreti G, Merli M, Ginanni CS, et al. Low-dose hepatitis B immune globulin and lamivudine for long-term prophylaxis of hepatitis B recurrence after liver transplantation. Transplant Proc 2004; 3: 535-8.

[57] Karademir S, Astacioglu H, Akarsu M, et al. Prophylactic use of lowdose, on-demand intramuscular hepatitis B immune globulin and lamivudine after liver transplant. Transplant Proc 2006; 38: 579-83.

[58] Zheng S, Chen Y, Liang T, et al. Prevention of hepatitis B recurrence after liver transplantation using lamivudine or lamivudine combined with hepatitis B immune globulin. Liver Transpl 2006; 12: 253-8.

[59] Rao W, Wu X, Xiu D. Lamivudine or lamivudine combined with hepatitis B immunoglobulin in prophylaxis of hepatitis B recurrence after liver transplantation: a meta-analysis. Transpl Int 2009; 22: 38794.

[60] Saab S, Ham MY, Stone MA, Holt C, Tong M. Decision analysis model for hepatitis B prophylaxis one year after liver transplantation. Liver Transpl 2009; 15: 413-20.

[61] Nath DS, Kalis A, Nelson S, Payne WD, Lake JR, Humar A. Hepatitis $\mathrm{B}$ prophylaxis post-liver transplant without maintenance hepatitis B immunoglobulin. Clin Transplant 2006; 20: 206-10.

[62] Angus PW, Patterson SJ, Strasser SI, McCaughan GW, Gane EJ. A randomized study of adefovir dipvoxil in place of HBIG in combination with lamivudine as post-liver transplant HBV prophylaxis. Hepatology 2008; 48: 1460-8.

[63] Yamamoto M, Little G, Imagawa DK. Hepatitis B immunoglobulin in preventing reinfection following liver transplantation. Expert Rev Anti Infect Ther 2009; 7: 321-8.

[64] Chang TT, Chao Y, Gorbakov VV, et al. Results of up to 2 years of entecavir versus lamivudine therapy in nucleoside-naïve $\mathrm{HBeAg}$ positive patients with chronic hepatitis. J Viral Hepat 2009; 16: 784-9.

[65] Han S, Chang T, Chao Y, et al. Four year entecavir treatment in nucleoside naïve HbsAg+ patients:results from studies ETV-022 and091. Hepatology 2007; 46: 654.

[66] Fung SK, Chae HB, Fontana RJ, et al. Virologic response and resistance to adefovir in patients with chronic hepatitis B. J Hepatol 2006; 44: 283-90.

[67] Limquiaco JL, Wong J, Wong VW, et al. Lamivudine monoprophylaxis and adefovir salvage for liver transplantation in chronic hepatitis B: a seven year follow-up study. J Med Virol 2009; 81:224-9.

[68] Camci C, Gurakar A, Rose J, et al. Liver transplantation for hepatitis B in the United States. Transplant Proc 2005; 37: 4350-3.

[69] Beckebaum S, Sotiropoulos GC, Klein CG, et al. Predictive factors of outcome in patients transplanted for hepatitis B. Transplantation 2009; 87: 872-81.

[70] Kim WR, Poterucha JJ, Kremers WK, Ishitani MB, Dickson ER. Outcome of liver transplantation for hepatitis B in the United States. Liver Transpl 2004; 10: 968-74.

[71] Roche B, Samuel D. Liver transplantation in viral hepatitis: prevention of recurrence. Best Pract Res Clin Gastroenterol 2009; 22: 1153-69.

[72] Patterson SJ, Angus PW. Post-liver transplant hepatitis B prophylaxis: the role of oral nucleos(t)ide analogues. Curr Opin Organ Transplant 2009; 14: 225-30. 